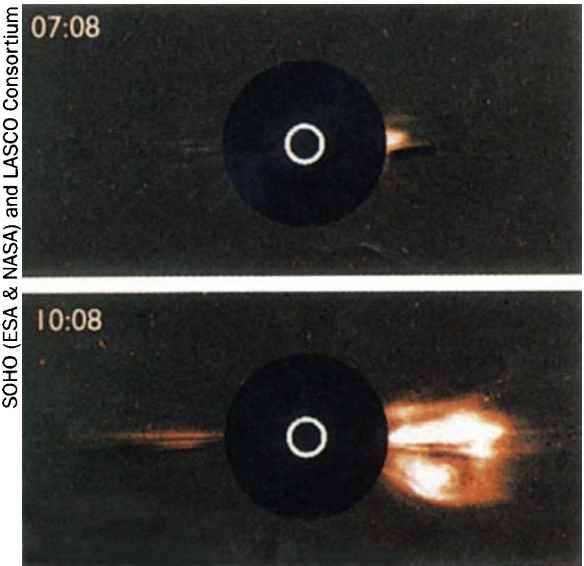

$13: 14$

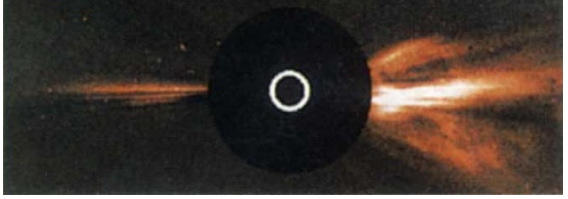

Images released today from the joint ESANASA SOHO project show a coronal mass ejection: billions of tonnes of gas burst out of the Sun at $550 \mathrm{~km}$ per second.

- Cobras/Samba and Intermarsnet entered the final selection round neck-and-neck according to scientists at the meeting. In particular, the meeting had to digest the significance of a recent US announcement that it intended to launch a similar mission to Cobras/Samba, called MAP.

But the Paris meeting concluded that MAP was "definitely an inferior mission", according to a senior official of the space science programme, who says that the performance of the US satellite had been "overstated".

In order to prevent the portfolio of ESA's missions early in the next decade being dominated by astronomy, the SSAC recommended that the next cornerstone mission be reserved for a planned mission to Mercury that would include an orbiting observatory and a landing craft (see Nature 371, 643; 1994). It also recommended that the next medium-sized mission be reserved for a project on Solar System research. "The success of Cobras/Sampas has been paid at a certain cost by the astronomy community," says one ESA official.

Declan Butler

\section{German research loses immunity to cuts}

Munich. German research minister Jürgen Rüttgers has not maintained the financial advantage he gained for his ministry last year when he secured an above-average budget rise of 2.8 per cent for 1996 over the 1995 level. The research ministry will not be exempt from a new round of budget cuts being imposed on all government spending as part of an emergency budget, introduced to combat the country's budget deficit resulting largely from the continued costs of reunification.

The federal government agreed last

\title{
Geneticist leaves Cambridge for industrial research post
}

London. One of Britain's leading geneticists is leaving a senior academic post to head the genetics research activities of SmithKline Beecham (SB), the world's tenth largest pharmaceutical company, which says that it is planning to base all future pharmaceutical and diagnostic products on knowledge of the human genome.

Peter Goodfellow, Arthur Balfour professor of genetics at the University of Cambridge, and well-known for a wide variety of contributions to genetics research - ranging from somatic cell genetics to sex determination - has announced his resignation, and will join SB at its main British research site at Harlow, outside London, at the beginning of July.

Goodfellow's arrival is being seen by the company not only as laying an important cornerstone for its genomics strategy, but also as evidence of a growing overlap between academic and industrial researchers, the distance between which has traditionally been greater in the United Kingdom than in countries such as the United States.

One aspect of this overlap, according to some, is that the cost of advanced research facilities in fields such as DNA sequencing is now so high that the private sector can offer more attractive basic research facilities than the academic sector. Goodfellow, for example, will have access to the privately held database of genomic sequences built up by Human Genome Sciences and the Institute for Genomic Research in Rockville, Maryland, in which SB has a major share.

"We are delighted to be bringing someone of Goodfellow's stature into the organization," says George Poste, director of research and development for the pharmaceutical company, formed in 1989 out of a merger between the US company SmithKline French and Britain's Beecham.

Poste has been largely responsible for a strategy that aims to make knowledge of the genome the starting point for all new diag-

Friday that the 1996 research budget of DM15.6 billion (US\$10.3 billon) now should be trimmed by two per cent for the rest of the year. Rüttgers says that new initiatives, such as the biotechnology and multimedia programmes, will be protected. But he has yet to say where he anticipated the cuts will fall. According to a spokeswoman for the ministry, such decisions are unlikely to be made before the summer, when the first round of talks regarding the 1997 research budget are due to be concluded. nostic and therapeutic products in SB by the end of the decade. Sequencing the human genome, he argues, is only the first step; equally difficult is learning how to exploit the knowledge that this produces. "The whole world of science has to spend a lot of time trying to assess the functional role of genes," he says. "Goodfellow's appointment is an expression of that reality."

Genomic knowledge, he says, will not be used only as the basis of new diagnostic tests and potential therapies. Another potential application is in the testing of new drugs before approval by regulatory authorities, attempting to understand the 'pharmacogenetic' basis of drug response at the molecular level - in other words why different people respond to drugs in different ways.

Goodfellow already has industrial experience. He has, for example, been a consultant for Amersham International and a founding member of the scientific advisory board of Sequana Therapeutics in California, which recently announced the discovery of the 'tubby' gene responsible for one type of obesity in mice (see Nature 380, 534 538 ; 1996).

$\mathrm{He}$ expresses both regret and relief at leaving the academic environment. "I've had a wonderful time at Cambridge,"

at Goodfellow: regret and says. "But there

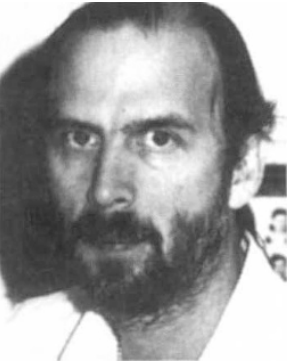

have been constraints. It has been a strain to maintain the infrastructure needed to carry out internationally competitive research and the financial restraints have been getting worse."

He will also be giving up the sex determination work that he has been involved in for the past ten years. But at the same time, he says that his new UK-based post, in which as a senior vice-president for research and development he will be one of the managers responsible for SB's worldwide research, will involve "taking the sort of science that we do in universities into an industrial context".

Meanwhile, Poste says that he also hopes that Goodfellow's arrival at the company will help to boost the morale of its scientists in Britain which, he admits, was badly shaken by his decision last year to close down part of its microbiological activity, and which is further undermined by talk of future job losses among research teams considered insufficiently productive. "This sends a signal that we are committed to the long-haul in the United Kingdom," he says.

David Dickson 